\title{
Fear and concerns of women delivering during coronavirus pandemic
}

\author{
Anupama Bahadur, Rajlaxmi Mundhra*, Rupendra Kuncham, \\ Jyotshna Kashibhatla, Neha Verma, Jaya Chaturvedi
}

Department of Obstetrics and Gynecology, All India Institute of Medical Sciences, Rishikesh, Uttarakhand, India

Received: 24 October 2020

Accepted: 04 December 2020

\author{
*Correspondence: \\ Dr. Rajlaxmi Mundhra, \\ E-mail: rmundhra54@yahoo.com
}

Copyright: (c) the author(s), publisher and licensee Medip Academy. This is an open-access article distributed under the terms of the Creative Commons Attribution Non-Commercial License, which permits unrestricted non-commercial use, distribution, and reproduction in any medium, provided the original work is properly cited.

\begin{abstract}
Literature is sparse regarding the fears and concerns of women delivering during COVID 19 pandemic. We interviewed 12 women delivering during the initial first week of lockdown period. There were three key concern of women- fear of being exposed at hospital, restricted number of hospital visitors made them confined and self-isolated thereby making them bored and frustrated, risk of baby being infected. Virtual communication through mobile was seen as a major support in all serving as a means of contact with their loved ones. Understanding a pregnant women's concern and fear during this pandemic will enable a health care worker in better counselling.
\end{abstract}

Keywords: COVID 19, Pregnancy, Fears, Anxiety

\section{INTRODUCTION}

The novel coronavirus namely SARS CoV2 has emerged as a potentially life-threatening condition with spread almost all over the world. World health organization has declared it as a global public health emergency. COVID 19 pneumonia was first detected in Wuhan, China in December 2019 and since then almost whole of the world is under its infectious attack. ${ }^{1}$ Pregnant woman undergoes physiological changes in her cardiorespiratory system making her a vulnerable group prone to develop respiratory infection. The previously identified strains of coronavirus family, namely severe acute respiratory syndrome coronavirus (SARS-CoV) and Middle East respiratory syndrome coronavirus (MERS-CoV) are both known to cause severe complications during pregnancy with need for endotracheal intubation, admission to an intensive care unit (ICU), renal failure and death. ${ }^{2,3}$ With the emergence of this new coronavirus strain and limited data regarding its impact on pregnancy outcomes, there remains an uncertainty among woman delivering during this phase, where no proven treatment exists.
Pregnancy is considered as one of the most intense and emotional phases in a women's life. The preparation to welcome the newborn child begins much before delivery. Things have changed drastically owing to the emergence of this highly contagious coronavirus strain. Worldwide, there is lockdown situation with restricted people mobility resulting in social isolation for majority. This has resulted in a sense of worry and anxiety among pregnant women. Stress and anxiety during pregnancy are known to be associated with hyperemesis gravidarum, preterm labour, low birth weight and lower APGAR score. ${ }^{4,5}$ As a preventive measure to reduce infection, Indian government also announced a lockdown initially for 21 days starting from 24th March 2020.We hypothesised that this sudden lockdown might have resulted in a sense of uncertainty and fear among those delivering during this period. With this aim, we interviewed postnatal women who had delivered during this initial lockdown phase to identify their fears and concerns.

We prospectively conducted a hospital-based qualitative study in maternity ward of a tertiary centre in Uttarakhand India. In depth interviews of 12 pregnant 
women delivering during this initial lockdown period. Semi structured interview with open ended questions mainly focusing on their specific source of fear and worries were employed during the data collection in the interview. Each interview lasted for half an hour and were aimed at letting the informant speak freely and without interruptions. Verbal informed consent was obtained from each participant prior to the interview with maintaining their privacy and confidentiality.

\section{Awareness about disease}

All the women were aware about the nature of this dreaded disease and were trying best use of hand rubs \& hand sanitizers provided to them by the hospital team to reduce the risk of getting infected.

As per our hospital infection prevention and control team, adequate spacing was kept between two hospital beds and each bed had a hand sanitizer kept over its rack. Each woman was also given a face mask. As a result, everyone was following the concept of social distancing with maintenance of personal hygiene.

\section{Cause of their concern and anxiety}

1) Fear and worry about their own health and their attendants- This started right after their entry into the hospital premise. Owing to current pandemic situation, every patient attending hospital underwent though a screening stage answering a checklist enquiring for their travel history, contact history or febrile illness associated with cough and shortness of breath. This resulted in an extra stress for them making them fearful 2) concern and worry that hospital itself is a potential source of acquiring infection and as such, 3 women attended postdated citing the reason that they waited for spontaneous delivery at home 3) sharing the maternity room with some unknown women (who might be a silent carrier of the virus) further added to their stress 4) stress of being monitored for signs and symptoms of COVID 19 5) frustration and anger that their relatives would avoid them after being discharged from hospital as they would fear themselves of contracting the disease 6) not being able to meet with their children back home was a major concern 7) worry that their child might be affected was a concern in all the mothers 7) prolonged neonatal admission of baby was another reason for their anxiety. Restricting the number of attendants in hospital further makes them self-isolated 8) all mothers were anxious to know if breastfeeding was safe or not.

\section{Challenges faced in hospital}

None of the women reported any challenge faced in terms of arranging food and medicine as the hospital was well prepared and had adequate stocks arranged.

\section{Coping strategies in hospital}

Virtual communication through mobile was a major support in all serving as a means of contact with their loved ones. Reading books and religious material was helpful in some women.

\section{DISCUSSION}

Prior to addressing the fears and concerns, it is crucial to understand why this happens. With focused listening sessions, we identified 3 key concerns of pregnant women 1) fear of being exposed at hospital and in turn taking the infection home thereby affecting their near and dear ones 2) restricted number of hospital visitors made them confined and self-isolated; acted as a cause of their boredom and frustration 3 ) risk of baby being affected.

Any women arriving in labor ward must be segregated based on hospital strategies into risk categories so that type of infection control precautions can be employed for the attending medical staff. Adequate patient counselling should be done at repeated intervals to minimize her fear of acquiring infection in hospital setting. Owing to highly contiguous nature of this infection, appropriate arrangement should be done during intrapartum period. She should be informed that at present there is no convincing evidence of vertical transmission and breastfeeding is safe. In a retrospective analysis of COVID-19 in pregnancy, it was seen that none of the women had detectable viral loads of SARS-CoV-2 in breastmilk. $^{6}$ A face mask should be worn while breast feeding to reduce the risk of droplet transmission. COVID 19 related stress and concerns have previously been evaluated by Rashidi et al. ${ }^{7}$

A potential limitation of this study was that it interviewed only woman who delivered, thereby leaving the other important subset of pregnant woman who comes for regular antenatal checkups. This subset might have some other additional fears and concerns which also needs to be addressed for better maternal and fetal wellbeing. Strength of this study is that it focuses on an important issue which need to be dealt with compassion.

\section{CONCLUSION}

Understanding a pregnant women's concern and fear during this pandemic will enable a health care worker in better counselling. Considering the impact of this global public health issue, we believe that addressing the issues brought out in our study would help in relieving a women's fears and concerns in a significant way.

Funding: No funding sources

Conflict of interest: None declared

Ethical approval: Not required 


\section{REFERENCES}

1. Zhu N, Zhang D, Wang W, Zhu N. A novel coronavirus from patients with pneumonia in China, 2019. N Engl J Med. 2020.

2. Wong SF, Chow KM, Leung TN, Ng WF, Ng TK, Shek CC, et al. Pregnancy and perinatal outcomes of women with severe acute respiratory syndrome. Am J Obstet Gynecol. 2004;191:292-7

3. Alfaraj SH, Al-Tawfiq JA, Memish ZA. Middle East respiratory syndrome coronavirus (MERS-CoV) infection during pregnancy: report of two cases \& review of the literature. J Microbiol Immunol Infect 2019;52:501-3.

4. Qiao Y, Wang J, Li J, Wang J. Effects of depressive and anxiety symptoms during pregnancy on pregnant, obstetric and neonatal outcomes: a followup study. J Obstet Gynaecol. 2012;32(3):237-40.
5. Alder J, Fink N, Bitzer J, Hösli I, Holzgreve W. Depression and anxiety during pregnancy: a risk factor for obstetric, fetal and neonatal outcome? A critical review of the literature. J Matern Feta Neonat Medic. 2007;20(3):189-209.

6. Chen H, Guo JMS, Chen W. Clinical characteristics and intrauterine vertical transmission potential of COVID-19 infection in nine pregnant women: a retrospective review of medical records. Lancet. 2020.

7. Fakari RF, Simbar M. Coronavirus pandemic and worries during pregnancy, a letter to the editor. Arch. Acad. Emerg. Med. 2020;8(1):e21.

Cite this article as: Bahadur A, Mundhra R, Kuncham R, Kashibhatla J, Verma N, Chaturvedi J. Fear and concerns of women delivering during coronavirus pandemic. Int J Reprod Contracept Obstet Gynecol 2021;10:330-2. 